\title{
Immunopharmacological Studies on TBX, a New Antiallergic Drug (3) Inhibitory Effects on Histamine Release from Lung Fragments and Bronchoconstriction in Guinea Pigs
}

\author{
Yukiyoshi YANAGIHARA, Hiroshi KASAI ${ }^{1}$, Shizuo MATSUI ${ }^{1}$ \\ and Kenji NINOMIYA ${ }^{1}$ \\ Clinical Research Center for Allergy, National Sagamihara Hospital. \\ Sagamihara, Kanagawa 228, Japan \\ ${ }^{1}$ Research Laboratories. Tokyo Tanabe Pharmaceutica! Co., Ltd., \\ Akabane-kita, Kita-ku, Tokyo 115, Japan
}

Accepted May 22, 1989

\begin{abstract}
The effects of 9 - methyl-3-(1H-tetrazol-5-yl)-4H-pyrido[1,2-a]pyrimidin4-one potassium salt (TBX), a new antiallergic drug. on histamine release from lung fragments, experimental asthma and isolated tracheal muscle were investigated in guinea pigs. TBX $\left(10^{-7}\right.$ to $\left.10^{-4} \mathrm{~g} / \mathrm{ml}\right)$ dose-dependently inhibited antigeninduced histamine release from lung fragments of guinea pigs passively sensitized with homologous IgE serum. Antigen inhalation-induced experimental asthma in passively sensitized animals was inhibited in a dose-dependent fashion by i.v. (1 to $5 \mathrm{mg} / \mathrm{kg}$ ) and p.o. (10 to $100 \mathrm{mg} / \mathrm{kg}$ ) administrations of TBX. In vivo bronchoconstriction by platelet-activating factor (PAF, i.v.) was also inhibited by TBX $(0.3$ to $10 \mathrm{mg} / \mathrm{kg}, i . v$.). However, high concentrations of TBX (more than $3 \times 10^{-4} \mathrm{~g} / \mathrm{ml}$ ) were needed to inhibit PAF-induced platelet aggregation in vitro. With regard to the effect on isolated tracheal muscle. TBX itself at concentrations higher than $10^{-5}$ $\mathrm{g} / \mathrm{ml}$ induced dose-dependent reduction in the resting tonus, which was not affected by pretreatment with propranolol. Neither the leukotriene $\mathrm{D}_{4}$-induced contraction nor the prostaglandin $F_{2 \alpha}$-induced one was specifically antagonized by TBX. The results obtained indicate that $T B X$ is an antiasthmatic agent effective in inhibiting both $\operatorname{lgE}$ - and PAF-induced bronchoconstriction, possibly by interfering with mediator release.
\end{abstract}

in the previous papers, 9-methyl-3-(1Htetrazol - 5-yl) - 4H - pyrido [1,2-a]pyrimidin-4one potassium salt (TBX) that shows no antagonistic actions on chemical mediators such as histamine and serotonin has been reported to be a new antiallergic drug capable of inhibiting both passive cutaneous anaphylaxis (PCA) and histamine release from mast cells in rodent models $(1,2)$. The potency of TBX to inhibit anaphylactic histamine release has also been shown to be much higher than that of disodium cromoglycate (DSCG) or tranilast. In addition, the antiallergic properties of TBX have been suggested to be different from those of DSCG and tranilast; for example. this agent was indeed effective in inhibiting homologous PCA in guinea pigs, known to be animals fairly insensitive to DSCG treatment.

On the other hand, numerous mediators, such as histamine and arachidonate metabolites, responsible for the airway constriction, have been implicated in the pathogenesis of allergic asthma. With regard to the arachidonate metabolites, particularly the slow reacting substance of anaphylaxis (SRS-A). TBX has been found to inhibit SRS-A release from human lung ( 3 ).

The above findings prompted us to examine the inhibitory activity of TBX on experimental asthma in animals. The main purpose of this paper is to study the antiasthmatic action of TBX in guinea pigs. The effect on in vivo bronchoconstriction induced 
by platelet-activating factor (PAF) was also investigated.

\section{Materials and Methods}

Animals: Male Hartley guinea pigs weighing 300 to $450 \mathrm{~g}$ were obtained from Shizuoka Laboratory Animal Center.

Chemicals: The chemicals used were TBX (Tokyo Tanabe). DSCG (Fujisawa), tranilast (Kissei), pyrilamine maleate (Sigma), propranolol hydrochloride (Sumitomo), isoproterenol bitartarate (Sigma). papaverine (Wako), theophylline (Wako), PAF (1-0alkyl-2-acetyl - sn-glyceryl - 3 - phosphrylcholine, Sigma), prostaglandin $F_{i \alpha}\left(P G F_{z \alpha}\right.$ Sigma), prostaglandin $E_{1}\left(P G E_{1}\right.$, Sigma) and leukotriene $\mathrm{D}_{4}\left(\mathrm{LTD}_{4}\right.$. Paesel $\mathrm{Gmbh} \& \mathrm{Co}$.) $\mathrm{PAF}, \mathrm{PGF}_{2} \alpha$ and $\mathrm{LTD}_{4}$ were dissolved in chloroform, ethanol and methanol, respectively. They were diluted in physiological saline or Tyrode's solution before use. Other chemicals were dissolved in physiological saline or Tyrode's solution.

Antigen-induced histamine release from lung fragments: Guinea pigs were passively sensitized with i.v. injection of $1 \mathrm{ml}$ of homologous anti-dinitrophenyl (DNP) IgE serm (1:1024 of 8 day homologous PCA titer) which had been prepared as previously described (1). After passive sensitization for $48 \mathrm{hr}$, they were bled and lung specimens were isolated. Lung fragments were prepared with a tissue sectioner (TC-2 Sorvall) and washed thoroughly with Tyrode's solution. The lung fragments $(200 \mathrm{mg})$ were suspended in $1.6 \mathrm{ml}$ of Tyrode's solution containing 20 $\mathrm{mM}$ HEPES buffer, preincubated for $15 \mathrm{~min}$ at $37^{\circ} \mathrm{C}$, challenged with DNP-conjugated bovine serum albumin (DNP-BSA) at a final concentration of $1 \mathrm{mg} / \mathrm{ml}$, and further incubated for $30 \mathrm{~min}$. Histamine concentration in the supernatant was determined by the enzymatic radioassay (4). The total content of histamine was also assayed in the intact tissue which had been boiled for $10 \mathrm{~min}$.

Experimental asthma induced by antigen inhalation: Guinea pigs were passively sensitized with i.v. injection of $1 \mathrm{ml} / \mathrm{kg}$ of homologous anti-DNP IgE serum. After $48 \mathrm{hr}$, they were placed in a body plethysmograph and challenged by inhalation of DNP-BSA without anesthesia and restraint. Aerosolization was performed by a nebulizer filled with $10 \mathrm{mg} / \mathrm{ml}$ of DNP-BSA solution at a flow rate of $5 \mathrm{l} / \mathrm{min}$ for $15 \mathrm{sec}$. Tidal volume was measured in conscious animals by transmitting changes in the body plethysmograph pressure to a differential pressure transducer (PDL-40GB. Kyowa Dengyo) as previously described (5) and recorded on a polygraph (polygraph 142-8. Sanei Sokki). A schematic diagram for the measurement of tidal volume

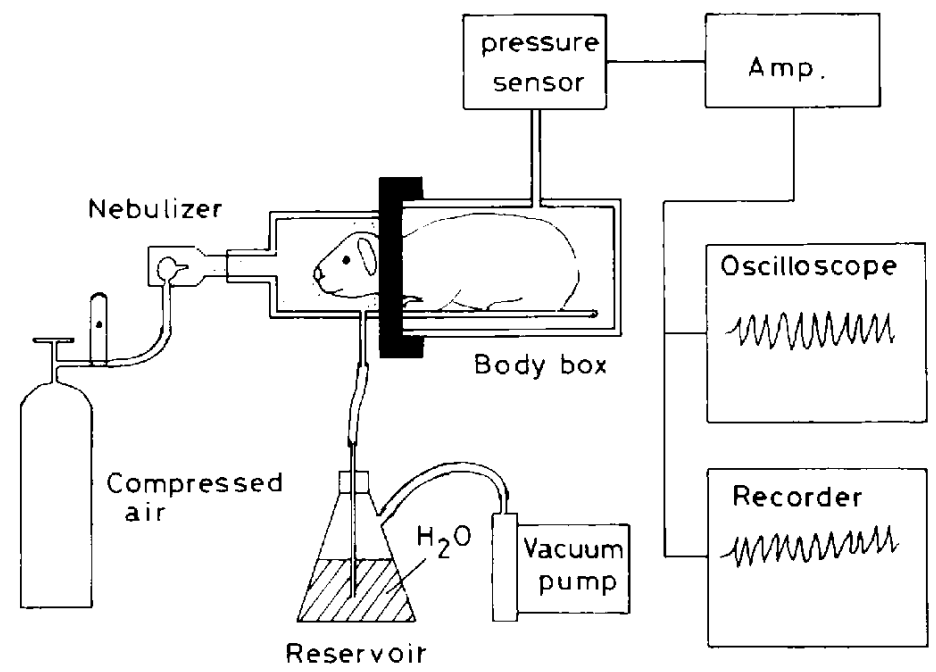

Fig. 1. Schematic diagram for the measurement of tidal volume in conscious guinea pigs passively sensitized with homologous anti-DNP lgE serum. 
is shown in Fig. 1.

Relaxant and contractile responses of isolated tracheal muscle: Tracheal strip chains of normal guinea pigs were prepared according to the method of Takagi and Takayanagi (6). The preparations were suspended in an organ bath $\left(37^{\circ} \mathrm{C}\right.$ ) containing $5 \mathrm{ml}$ of Tyrode's solution, which was gassed with a mixture of $95 \% \mathrm{O}_{2}$ and $5 \% \mathrm{CO}_{2}$, under a load of $1 \mathrm{~g}$. Relaxant and contractile responses were measured using a isotonic transducer (TD-112S, Nihon Kohden) and displayed on a recorder (WT-685G, Nihon Kohden). With regard to chemical mediator-induced contraction of isolated tracheal muscle, both $\mathrm{LTD}_{4}$ $\left(10^{-9} \mathrm{~g} / \mathrm{ml}\right)$ and $P F_{2 \alpha}\left(3 \times 10^{-7} \mathrm{~g} / \mathrm{ml}\right)$ were used as contractile agents.

Bronchoconstriction induced by PAF: Guinea pigs were anesthetized with i.p. injection of urethane $(1.5 \mathrm{~g} / \mathrm{kg})$. trachea was cannulated for the measurement of bronchoconstriction, and spontaneous breathing was fully arrested with gallamine triethiodide (1 $\mathrm{mg} / \mathrm{kg}$, i.v.). Animals were then ventilated with a small animal respirator (Ugo Basile) at the rate of 70 breaths $/ \mathrm{min}$ ( 5 to $8 \mathrm{ml}$ of stroke volume). Airflow was measured with a bronchospasm transducer (Ugo Basile) connected to a side arm of the tracheal cannula and expressed as a percentage of maximum bronchoconstriction obtained by clamping off the trachea. PAF in a dose of $0.3 \mu \mathrm{g} / \mathrm{kg}$ was injected into the jugular vein in order to induce bronchoconstriction in vivo.

PAF-induced platelet aggregation: Blood was collected from the abdominal aorta of normal guinea pigs after light anesthesia with ether, and whole blood was mixed with $3.8 \%$ sodium citrate solution at the ratio of 9 to 1 . The blood was centrifuged at $190 \times \mathrm{g}$ for 10 min, and the top platelet-rich plasma (PRP) was carefully removed. The erythrocyte pellet was further centrifuged at $1.500 \times \mathrm{g}$ for 10 min, and the supernatant (platelet poor plasma: PPP) was obtained. Platelets in the PRP were adjusted to a concentration of $450,000 / \mu 1$ using PPP. Ten microliters of PAF solution (final concentration of $5 \times 10^{-6} \mathrm{~g} / \mathrm{ml}$ ) was added to $250 \mu l$ of PRP, and platelet aggregation was monitored by measuring changes in turbidity with a 6-channel aggregometer, model RMA61 (Rikadenki) at $37^{\circ} \mathrm{C}$. Platelet aggregation was expressed in terms of percent change; it was calculated from the maximum transmittance change by assigning the transmittance of unstimulated PRP to be $0 \%$ and that of PPP to be $100 \%$.

Statistical analysis: Results were expressed as the mean \pm S.E. Statistical significance was determined by Student's $t$-test. ED50 was obtained by the logit method.

\section{Results}

Effect on antigen-induced histamine release from lung fragments of guinea pigs: The fragments were preincubated with the drugs for $15 \mathrm{~min}$ before antigen challenge. As shown in Fig. 2, TBX at concentrations of $10^{-7}$ to $10^{-4} \mathrm{~g} / \mathrm{ml}$ dose-dependently inhibited antigen-induced histamine release from lung fragments of guinea pigs passively sensitized with homologous anti-DNP IgE serum. Similarly, tranilast dose-dependently inhibited histamine release. In contrast, DSCG exerted a weak inhibitory influence on histamine release. Note that the inhibitory action of TBX at concentrations of $10^{-7}$ to $10^{-5} \mathrm{~g} / \mathrm{ml}$ upon histamine release was superior to that of

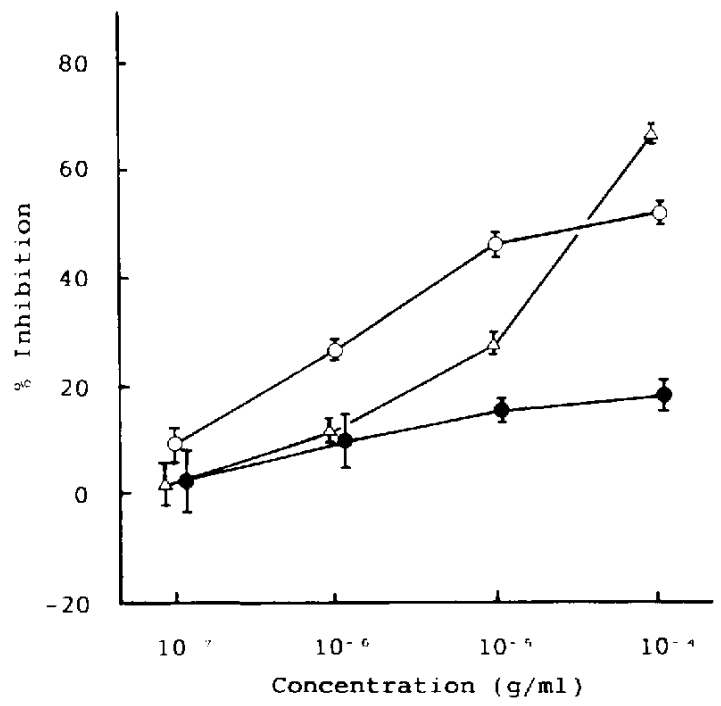

Fig. 2. Effect of TBX (-O-), DSCG (-- - ) and tranilast $(-\triangle-)$ on antigen-induced histamine release from lung fragments of guinea pigs passively sensitized with homologous anti-DNP lgE serum. Net histamine release in the control was $16.6 \pm 0.28 \%$. Each point represents the mean \pm S.E. of 3 to 6 experiments. 


\section{tranilast.}

Effect on experimental asthma by antigen inhalation: A typical example of experimental asthma induced by antigen inhalation in a conscious guinea pig passively sensitized with homologous anti-DNP $\operatorname{lgE}$ serum is shown in Fig. 3A. Antigen inhalation resulted in a rapid decrease in tidal volume together with disorder of respiration: the lowest tidal volume (about 50\%) and the highest increase in respiratory rate were observed at 2 to $3 \mathrm{~min}$ after antigen inhalation, and they were gradually restored as time passed. In contrast, Fig. $3 \mathrm{~B}$ shows one example of strong inhibition of experimental asthma by $5 \mathrm{mg} / \mathrm{kg}$ of TBX, which was intravenously administered 3 min before antigen inhalation. The results pertaining to the i.v. administration of TBX, DSCG and pyrilamine at 3 min prior to antigen challenge are summarized in Fig. 4. TBX ( 1 to $5 \mathrm{mg} / \mathrm{kg}$, i.v.) dose-dependently inhibited antigen inhalation-induced experimental

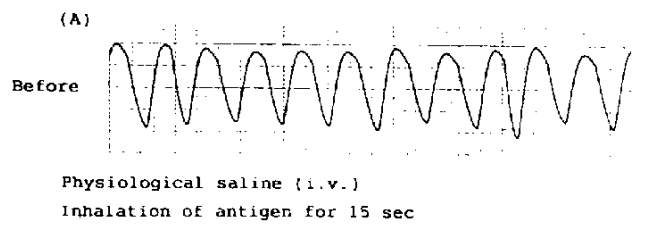

$$
\begin{aligned}
& \text { mannmann }
\end{aligned}
$$

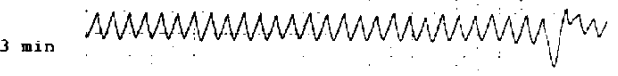

10 ain MWMWWWWMWMWM
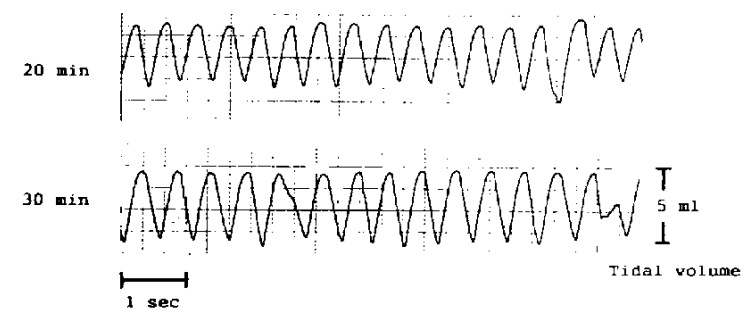

asthma as shown in Fig. 4A; the i.v. administration of 2.5 to $5 \mathrm{mg} / \mathrm{kg}$ of the drug induced the significant inhibition of experimental asthma at the early phase of the decreases in tidal volume. Similar results were obtained with pyrilamine $(0.1 \mathrm{mg} / \mathrm{kg}$, i.v.) (Fig. 4B). but DSCG (25 $\mathrm{mg} / \mathrm{kg}$, i.v.) did not inhibit this experimental asthma. Oral administration of $T B X$ in doses of 10 to $100 \mathrm{mg} / \mathrm{kg}$ adminis tered either 2 or $8 \mathrm{hr}$ before antigen inhalation also showed the dose-dependent inhibition of experimental asthma (Fig. 5). Note that TBX, which was administered orally $8 \mathrm{hr}$ before antigen challenge, was still active in the inhibition of experimental asthma (Fig. $5 \mathrm{~B})$, suggesting that this drug is long-acting in guinea pigs.

Relaxant effect on isolated tracheal muscle of guinea pigs: As illustrated in Fig. 6, TBX at high concentrations of $10^{-5}$ to $10^{-3} \mathrm{~g} / \mathrm{ml}$ induced the dose-dependent reduction in the resting tonus of the tracheal strip chains of

(') )
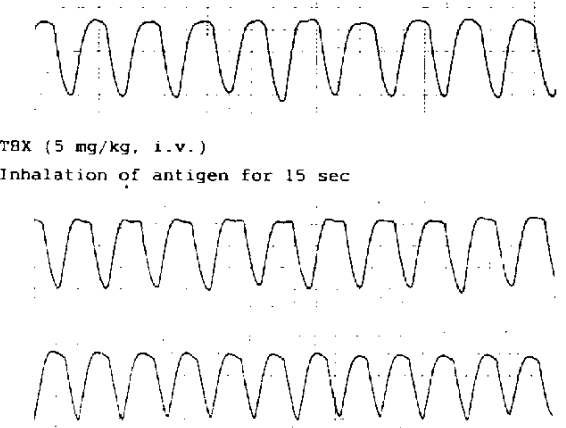

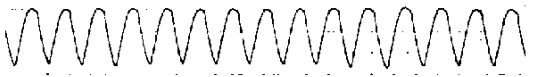
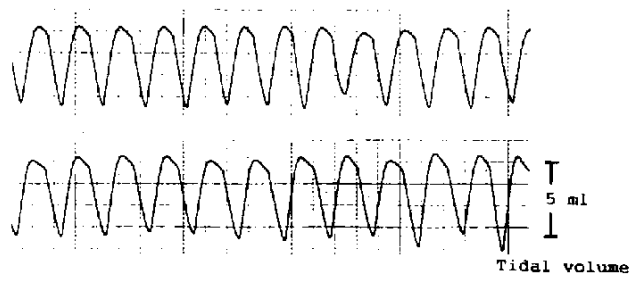

Fig. 3. Experimental asthma induced by antigen inhalation in a control guinea pig (A) and its inhibition by i.v. administration of $5 \mathrm{mg} / \mathrm{kg}$ of TBX (B). Animals were passively sensitized with homologous antiDNP IgE serum. Either physiological saline or TBX was administered i.v. 3 min before antigen inhalation (DNP-BSA). 


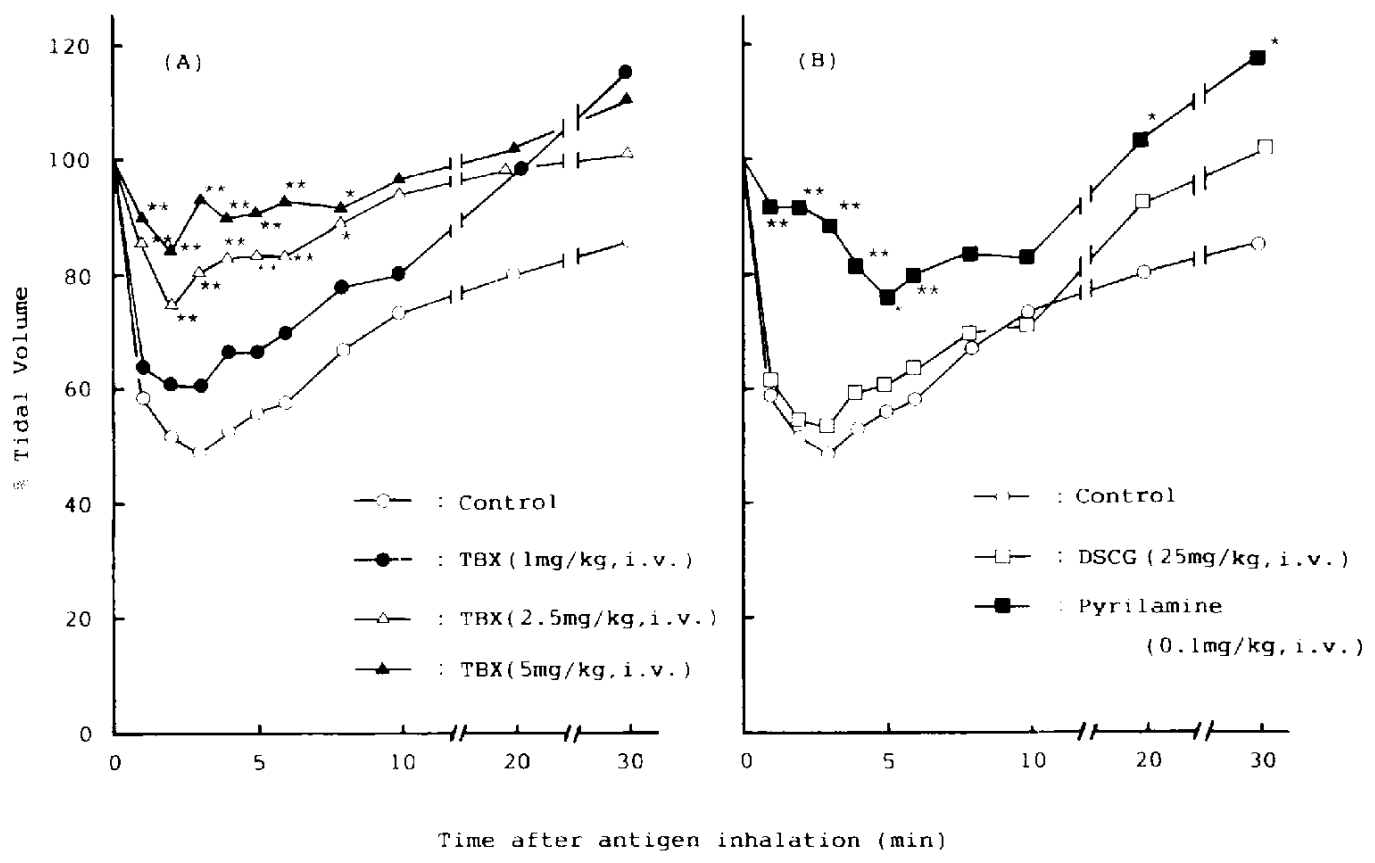

Fig. 4. Effect of TBX (A). DSCG and pyrilamine (B) on antigen inhalation-induced experimental asthma in conscious guinea pigs passively sensitized with homologous anti-DNP IgE serum. Drugs were given i.v. $3 \mathrm{~min}$ before antigen challenge. Each point represents the mean \pm S.E. of 8 animals. In general, the S.E. of each point was within $15 \%$ of the mean. ${ }^{*},{ }^{*}$ : Statistically significant difference from the control at $P<0.05$ and $P<0.01$, respectively.

guinea pigs. However, isoproterenol, papaverine and theophylline (less than $10^{-5} \mathrm{~g} / \mathrm{ml}$ ) showed stronger reduction in the resting tonus than did TBX. The relaxant potency of TBX was compared with that of theophylline, papaverine or isoproterenol; EC50 values of all these drugs were $8.2 \times 10^{-5} \mathrm{~g} / \mathrm{ml}$ for TBX. $1.2 \times 10^{-5} \mathrm{~g} / \mathrm{ml}$ for theophylline, $2.1 \times 10^{-7} \mathrm{~g} /$ $\mathrm{ml}$ for papaverine and $7.1 \times 10^{-10} \mathrm{~g} / \mathrm{ml}$ for isoproterenol, respectively. Further experiments were carried out to study whether TBXinduced reduction in the resting tonus was affected by pretreatment with propranolol $\left(10^{-6} \mathrm{~g} / \mathrm{ml}\right)$. One example is shown in Fig. 7 . Propranolol pretreatment resulted in no abrogation of TBX-induced reduction in the resting tonus. Note that isoproterenol-induced reduction was completely blocked by such pretreatment.

Effect on $\mathrm{LTD}_{4}$ - or $\mathrm{PGF}_{2 \alpha^{-}}$induced contraction of isolated tracheal muscle of guinea pigs: The tracheal strip chains were pretreated for 5 min with TBX at a concentration of $10^{-5}$ $\mathrm{g} / \mathrm{ml}$, which produced little relaxant effect on the resting tonus, and $\mathrm{LTD}_{4}$ or $\mathrm{PGF}_{2} \alpha$ was then added. TBX inhibited neither $\mathrm{LTD}_{4}$ induced contraction (100 versus $92.8 \pm 1.6$ in terms of percent change, $n=3$ ) nor $\mathrm{PGF}_{2 \alpha^{-}}$ induced contraction (100 versus $98.7 \pm 5.2 \%$, $n=3$ ).

Effect on PAF-induced bronchoconstriction in guinea pigs: As indicated in Table 1 . $\operatorname{TBX}(0.3$ to $10 \mathrm{mg} / \mathrm{kg}$, i.v. $)$, administered 2 min before PAF injection, dose-dependently inhibited PAF-induced bronchoconstriction, and significant inhibition was obtained with this drug (1 to $10 \mathrm{mg} / \mathrm{kg}$, i.v.). In contrast, DSCG $(10 \mathrm{mg} / \mathrm{kg}$, i.v.) was ineffective for inhibiting PAF-induced bronchoconstriction.

Effect on PAF-induced platelet aggregation in guinea pigs: A typical example is shown in Fig. 8 , and the results are summarized in Table 2. $P A F-i n d u c e d$ platelet aggregation was dose-dependently inhibited by TBX $\left(3 \times 10^{-4}\right.$ to $\left.3 \times 10^{-3} \mathrm{~g} / \mathrm{ml}\right)$ as well as by $\mathrm{PGE}_{1}\left(3 \times 10^{-8}\right.$ to $3 \times 10^{-7} \mathrm{~g} / \mathrm{ml}$ ), one of the anti-aggregating 


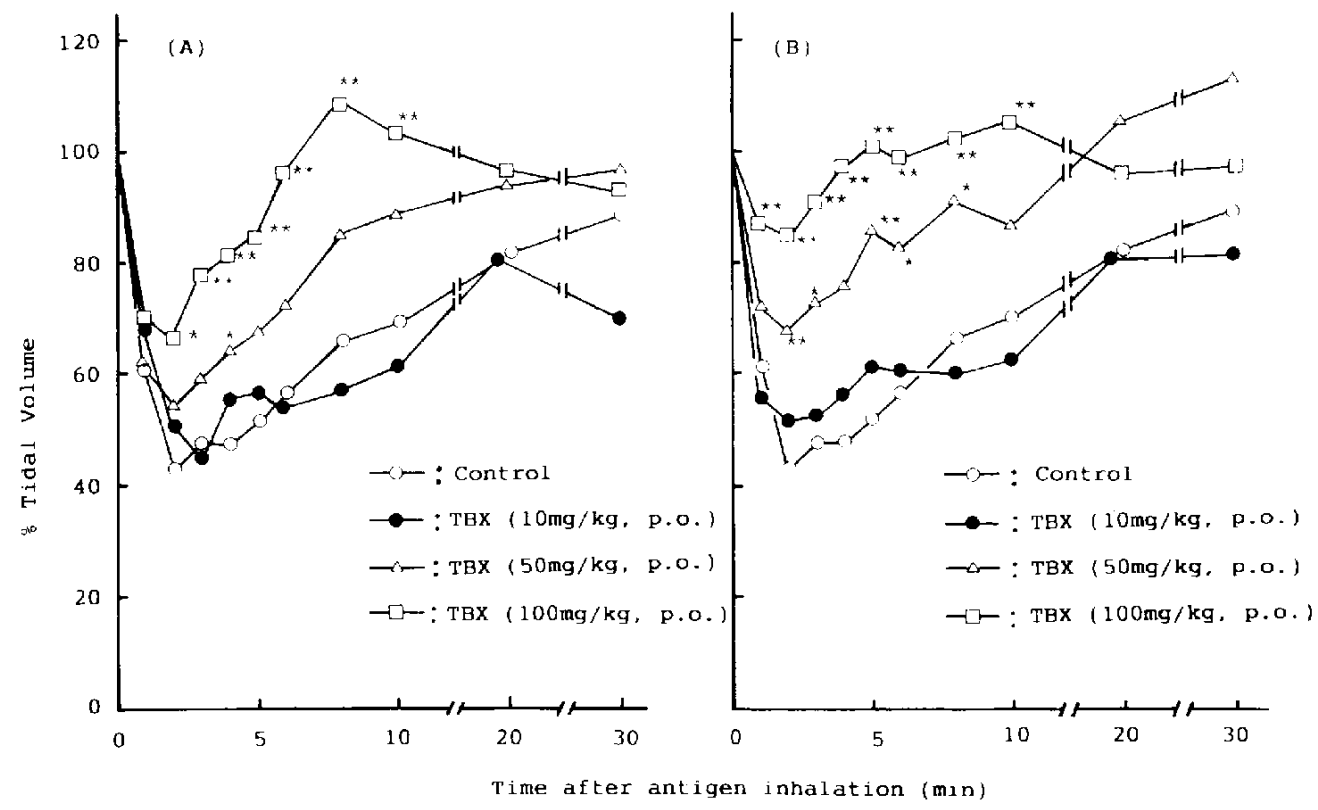

Fig. 5. Effect of TBX on antigen inhalation-induced experimental asthma in conscious guinea pigs passively sensitized with homologous anti-DNP IgE serum. TBX was given p.o. either 2 (A) or $8 \mathrm{hr}$ (B) before antigen inhalation. Each point represents the mean \pm S.E. of 6 or 7 anintals. In general, the S.E. of each point was within $15 \%$ of the mean. ${ }^{*},{ }^{* *}$ : Statistically significant difference from the control at $P<0.05$ and $P<0.01$, respectively.

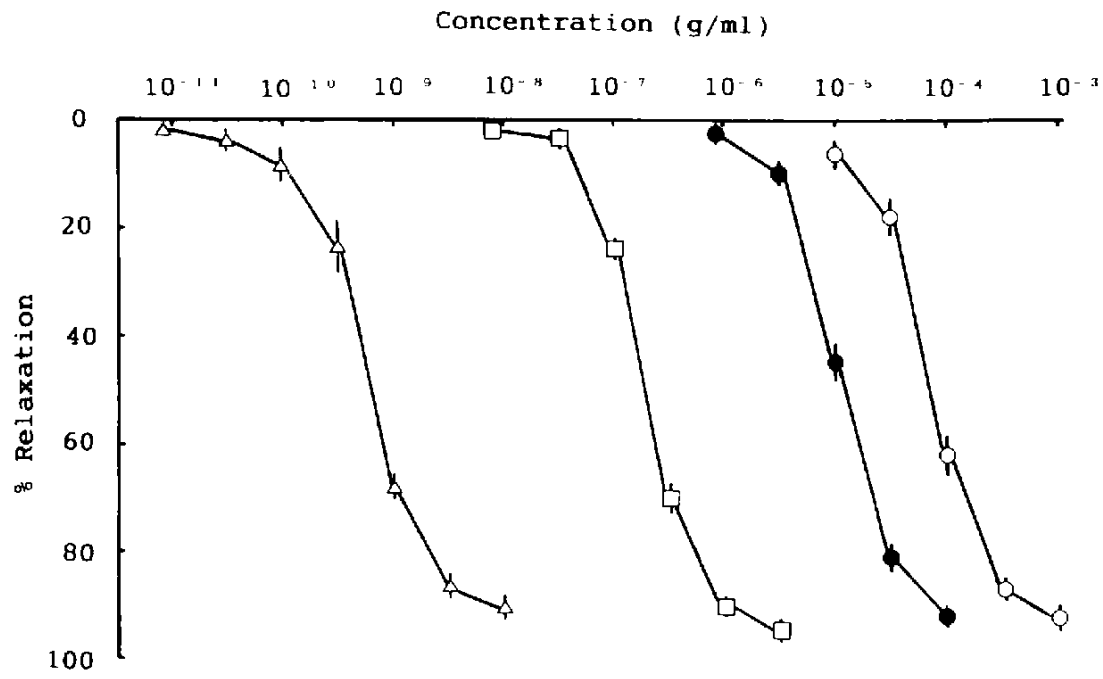

Fig. 6. Relaxant effect of TBX (-O-), theophylline (-O-), papaverine $(-\square-)$ and isoproterenol $(-\Delta-)$ on the resting tonus of isolated tracheal strip chains of normal guinea pigs. Each point represents the mean $\pm S$.E. of 6 or 7 experiments.

PGs. Note that much higher concentrations of TBX than those of $P G E_{1}$ were needed to induce such inhibition.

\section{Discussion}

The present results, in agreement with 


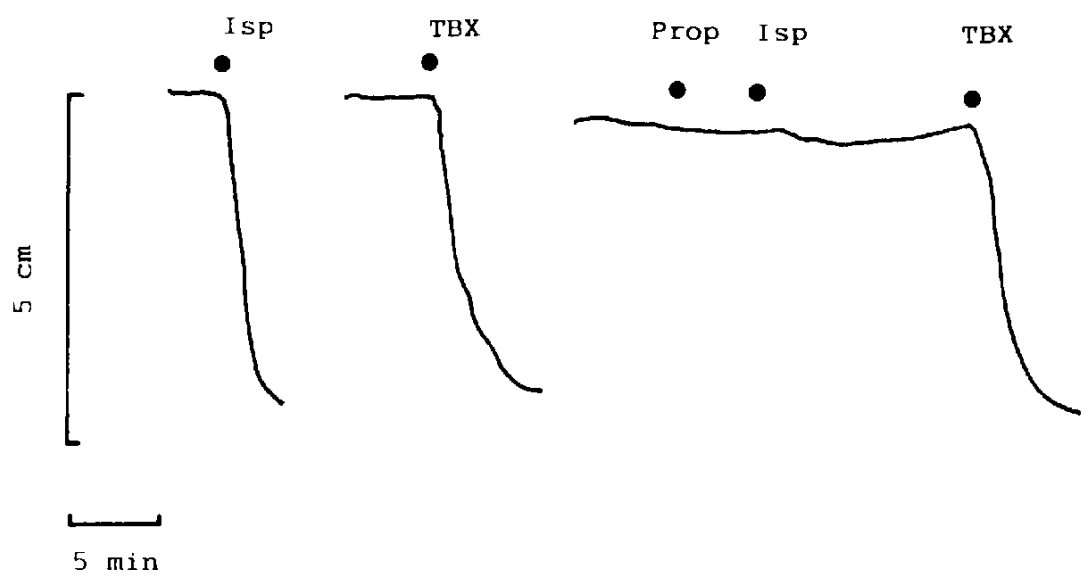

Fig. 7. Effect of pretreatment with propranolol (Prop. $\left.10^{-6} \mathrm{~g} / \mathrm{ml}\right)$ on TBX $\left(3 \times 10^{-4} \mathrm{~g} / \mathrm{ml}\right)$ - or isoproterenol ( $I s p, 3 \times 10^{-9} \mathrm{~g} / \mathrm{ml}$ )-induced reduction of the resting tonus of guinea pig tracheal strip chains.

Table 1. Effect of TBX and DSCG on PAF-induced bronchoconstriction in guinea pigs

\begin{tabular}{|c|c|c|}
\hline Drug & $\begin{array}{c}\text { Dose } \\
(\mathrm{mg} / \mathrm{kg})\end{array}$ & $\begin{array}{l}\% \text { Increase in } \\
\text { respiratory overflow }\end{array}$ \\
\hline Control & - & $74.3 \pm 4.4$ \\
\hline \multirow[t]{3}{*}{ TBX } & 0.3 & $56.6 \pm 15.8$ \\
\hline & 1 & $26.9 \pm 11.7^{* *}$ \\
\hline & 10 & $15.0 \pm 5.5^{* *}$ \\
\hline $\mathrm{DSCG}$ & 10 & $76.3 \pm 13.5$ \\
\hline
\end{tabular}

Drugs were given i.v. $2 \mathrm{~min}$ before PAF $(0.3 \mu \mathrm{g} / \mathrm{kg})$ injection. Each value represents the mean $\pm S . E$. of 5 to 10 animals. **: Statistically significant difference from the control at $P<0.01$

previous observations $(1,2)$, indicate that TBX is a potent inhibitor of $\operatorname{lgE}$-mediated histamine release from guinea pig lung. The prophylactic effects of TBX on antigen inhalation-induced experimental asthma were further studied using body plethysmography in conscious guinea pigs passively sensitized with homologous $\lg E$ serum. As expected, TBX ( 1 to $5 \mathrm{mg} / \mathrm{kg}$, i.v. and 10 to $100 \mathrm{mg} / \mathrm{kg}$. p.o.) dose-dependently inhibited the decrease in tidal volume caused by antigen inhalation. Interestingly, TBX was still active in the inhibition of experimental asthma even when administered p.o. $8 \mathrm{hr}$ prior to the challenge. suggesting that this drug is long-acting in guinea pigs. No significant inhibition of this experimental asthma, however. was seen in animals treated with DSCG $(25 \mathrm{mg} / \mathrm{kg}, i . v$.). as already confirmed by many investigators $(7-10)$, demonstrating that DSCG had little or no ability to inhibit guinea pig models. It should be emphasized that treatment with pyrilamine, one of the potent antihistamines, resulted in no complete abrogation of experimental asthma, suggesting that other mediators except for histamine are also responsible for the airway constriction. For example, both lipoxygenase and cyclooxygenase products of arachidonate are also considered to be potent constrictors of airways (11-16). In particular, $\mathrm{LTC}_{4}, \mathrm{LTD}_{4}$ and $\mathrm{LTE}_{4}$. known to comprise SRS-A (17) and to be products of the lipoxygenase pathway. have been shown to be more potent than histamine in causing contraction of both central and peripheral airways in animals and humans (18-20). Although the inhibitory effect of TBX on SRS-A release from guinea pig lung was not investigated in the present study, this agent has been reported to inhibit $\operatorname{lgE}$ mediated SRS-A release from human lung (3). Thus, it is suggested that the inhibition of not only histamine release but also SRS-A release may be responsible for the antias- 

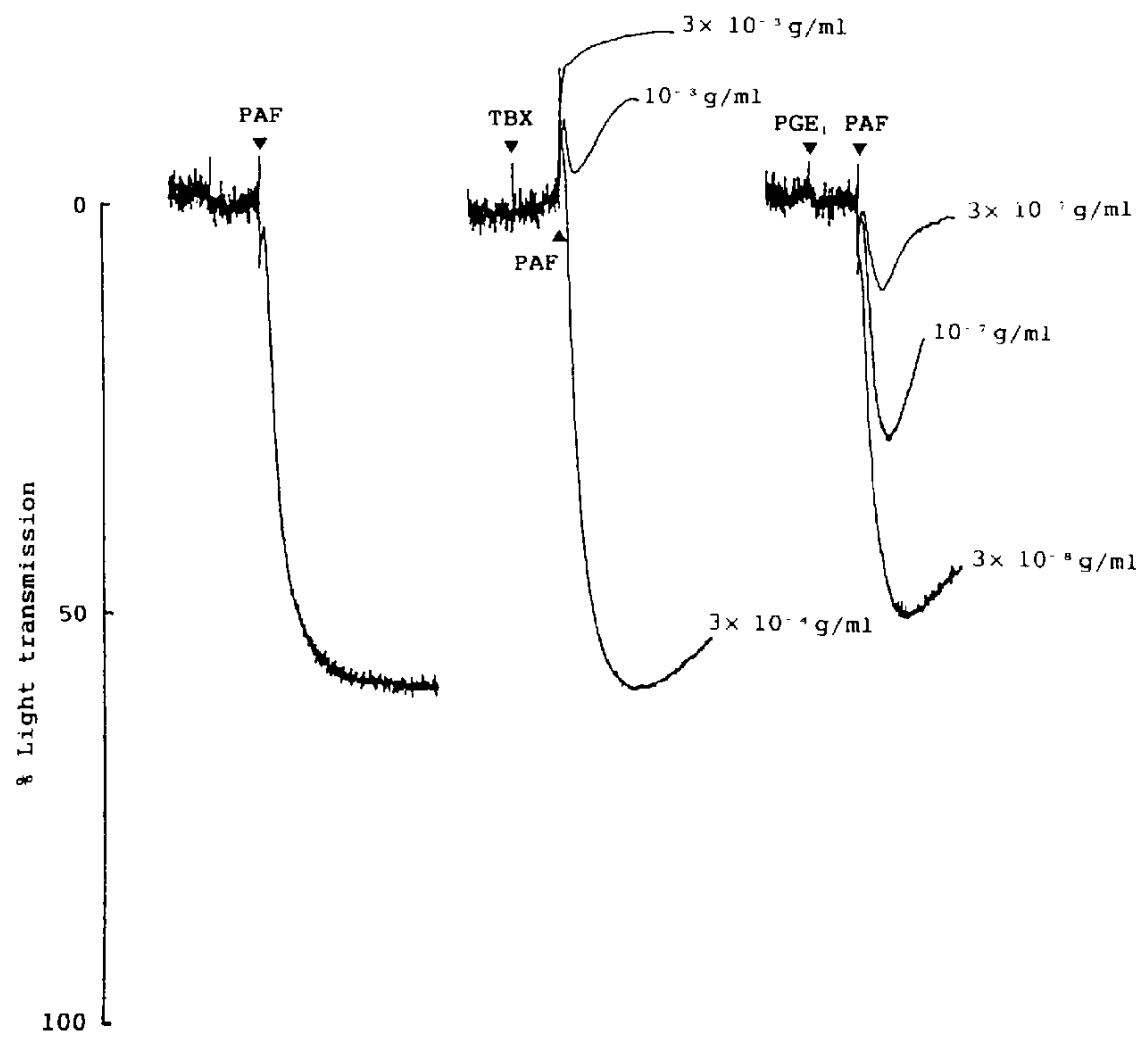

Fig. 8. Inhibitory effect of $T B X$ and $P G E_{1}$ on PAF-induced platelet aggregation in guinea pigs.

Table 2. Inhibitory effect of TBX and PGE

\begin{tabular}{ccc}
\hline Drug & Concentration $(\mathrm{g} / \mathrm{m} \mid)$ & \% Inhibition \\
\hline TBX & $10^{-4}$ & $2.4 \pm 1.4$ \\
& $3 \times 10^{-4}$ & $15.6 \pm 7.5$ \\
& $10^{-3}$ & $73.3 \pm 9.6$ \\
PGE $_{1}$ & $3 \times 10^{-3}$ & 100 \\
& $10^{-8}$ & $0.1 \pm 1.7$ \\
& $3 \times 10^{-8}$ & $9.7 \pm 4.9$ \\
& $10^{-7}$ & $78.4 \pm 10.2$ \\
\hline
\end{tabular}

Each value represents the mean \pm S.E. of 3 to 5 experiments.

thmatic activity of TBX in guinea pigs. On the other hand, cyclooxygenase products of arachidonate metabolism such as $\mathrm{PGD}_{2}$ and $\mathrm{PGF}_{2 \alpha}$ have also been demonstrated to play an important role in the airway constriction $(21,22)$. However, it is unknown at present whether TBX inhibits the generation of cyclooxygenase products in guinea pig lung during IgE-mediated hypersensitivity reac- tions; there is no information as to whether this drug has the ability to inhibit cyclooxygenase as well as lipoxygenase.

With regard to antagonistic actions on synthetic lipoxygenase and cyclooxygenase products, neither $\mathrm{LTD}_{4}{ }^{-}$nor $\mathrm{PGF}_{2} \alpha^{- \text {induced }}$ bronchoconstriction of guinea pig trachea in vitro was affected by $10^{-5} \mathrm{~g} / \mathrm{ml}$ of TBX. which exerted little influence on the resting 
tonus of the tracheal smooth muscle. The results that TBX displayed no inhibition of bronchoconstriction caused by $\mathrm{LTD}_{4}$ and $\mathrm{PGF}_{2 \alpha}$ are consistent with the previous findings demonstrating that no inhibition of rat skin reactions induced by histamine. serotonin and bradykinin was obtained with TBX (1). These observations strongly suggest that the antiasthmatic activity of TBX in guinea pigs is not due to antagonistic actions on histamine and arachidonate metabolites responsible for bronchoconstriction. Nevertheless, it ought to be mentioned that TBX itself at concentrations higher than $10^{-5} \mathrm{~g} / \mathrm{ml}$ induced the dose-dependent reduction in the resting tonus of isolated guinea pig trachea muscle. In addition. TBX-induced reduction in the resting tonus was not affected by pretreatment with propranolol, thus suggesting that such reduction is not mediated by a $\beta$ adrenergic mechanism. This suggestion is further supported by our previous findings that propranolol treatment did not modify TBX's inhibition of rat homologous PCA (1). TBX has been found to have an inhibitory activity on cyclic AMP-dependent phosphodiesterase derived from lung (2): this may be one of the mechanisms by which TBX induces a reduction in the resting tonus of guinea pig tracheal muscle.

Most interesting are the observations that TBX inhibits in vivo bronchoconstriction induced by PAF, known to be one of the important mediators of immediate hypersensitivity (23-26). Indeed, TBX (0.3 to $10 \mathrm{mg} / \mathrm{kg}$. i.v.), but not DSCG $(10 \mathrm{mg} / \mathrm{kg}$, i.v.), displayed the dose-dependent inhibition of PAF-induced bronchoconstriction in guinea pigs. Such inhibition, however, does not seem to be based on the direct antagonistic action on PAF, since high concentrations of TBX (more than $3 \times 10^{-4} \mathrm{~g} / \mathrm{ml}$ ) were required to inhibit PAF-induced platelet aggregation in vitro. Although in vivo bronchoconstriction by PAF has been reported to be fully plateletdependent $(25,27,28)$, little is known about this bronchoconstriction mechanism. A few candidates have been consequently suggested by several investigators as mediators of PAF-induced bronchoconstriction $(24,25$. 29). For example, ADP, arachidonate metabolites and $\mathrm{Ca}^{2+}$, which are released from stimulated platelets or other cells, have been shown to be indirectly involved in PAFinduced bronchoconstriction in vivo. Es pecially, lipoxygenase but not cyclooxygenase products of arachidonate are now considered to play a key role in the bronchoconstricting effect of PAF, because lipoxygenase inhibitors, LT antagonists and LT synthesis inhibitors are known to be effective in inhibiting PAF-induced bronchoconstriction (24, 25). Therefore, more detailed experiments are needed to investigate the mechanism by which TBX inhibits PAF-induced bronchoconstriction.

\section{References}

1 Yanagihara, Y., Kasai, H., Kawashima, T. and Shida, T.: Immunopharmacological studies on TBX, a new antiallergic drug. (1) Inhibitory effects on passive cutaneous anaphylaxis in rats and guinea pigs. Japan. J. Pharmacol. 48, 91 101 (1988)

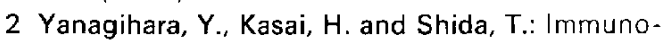
pharmacological studies on TBX, a new antiallergic drug. (2) Inhibitory effects on histamine release from peritoneal mast cells and lung fragments of rats. Japan. J. Pharmacol. 48, 103-112 (1988)

3 Kawashima, T., Tomioka, H. and Yoshida, S.: Inhibition of chemical mediator release from human leukocytes and lung fragments by TBX. Japan. J. Allergol. 37, 438-447 (1988) (Abs. in English)

4 Yanagihara, $Y$. and Shida, T: Immunopharmacological actions of the new antiallergic drug 11 . oxo-11 H-pyrido [2,1-b] quinazoline-2-carboxylic acid. Effects on type I hypersensitivity reactions in human leukocytes and in human and monkey lungs. Arzneimittelforschung 36, 16271631 (1986)

5 Yanagihara, Y., Abe, T., Kuroda, T. and Shida, T.: Immunopharmacological actions of the new antiallergic drug butyl $3^{r}$-(1H-tetrazol-5-yl) oxanilate. 3rd Communication: Inhibitory effects on histamine release from lung fragments. Schultz-Dale reaction in isolated tracheal muscle and experimental asthma. Arzneimittelforschung 38, 80-83 (1988)

6 Takagi, K. and Takayanagi, I.: Chemicopharma cological studies on antispasmodic action. XV. Nonspecific antispasmodic action on tracheal muscle. Chem. Pharm. Bull. (Tokyo) 6, 716-720 (1958)

7 Martin, L.E.: Inhibition of cellular anaphylaxis by 
beta-stimulants. Post-grad. Med. J. 47, Supp. 26-30 (1971)

8 Kuriki, H., Saijo, T., Ashida, Y. and Maki, Y.: Effect of 6-ethyl-3-(1H-tetrazo!-5-yl)chromone (AA-344) on the immediate and delayed hypersensitivity reactions. Japan. J. Pharmacol. 29, 733-744 (1979)

9 Taylor, W.A. and Roitt, I.M.: Effect of disodium cromoglycate on various types of anaphylactic reaction in the guinea pig. Int. Arch. Al!ergy Appl. |mmunol. 45, 795-807 (1973)

10 Lopez, M. and Bloch, K.J.: Effect of disodium cromoglycate on certain passive cutaneous anaphylactic reactions. J. Immunol. 103, 14281430 (1969)

11 Fish, J., Ankin, M., Adkinson, N.F., Jr. and Peterman, $V$.: Indomethacin modification of immediate-type immunologic airways response in allergic asthmatic and non-asthmatic subjects. Am. Rev. Resp. Dis. 123, 609-614 (1981)

12 Hyman, A., Spannhake, E. and Kadowitz, P.: State of the art, prostaglandins and the lung. Am. Rev. Resp. Dis. 117, 111-136 (1978)

13 Lewis, F. and Austen, K.F.: Nonrespiratory functions of pulmonary cells: the mast cell. Fed. Proc. 36, 2676-2683 (1977)

14 Moncada. S. and Vane, J.: Pharmacology and endogenous roles of prostaglandin, endoperoxides. thromboxane $A_{2}$ and prostacyclin. Pharmacol. Rev. 30, 293-331 (1979)

15 Piper, P. and Samhoun, M.: The mechanism of action of leukotriene $C_{4}$ and $D_{4}$ in guinea pig isolated perfused lung and parenchymal strips of guinea pig, rabbit and rat. Prostaglandins 21, 793-803 (1982)

16 Schulman, E., Newbah, H., Demers, L., Fitzpatrick, F. and Adkinson, N.F., Jr.: Anaphylactic release of thromboxane $A_{2}$, prostaglandin $D_{2}$. and prostacyclin from human lung parenchyma. Am. Rev. Resp. Dis. 124, 402-406 (1981)

17 Samuelsson, B., Hammarstrom, S., Murphy, R.C. and Borgeat, P.: Leukotrienes and slowreacting substances of anaphylaxis (SRS-A). Allergy 35, 375-381 (1980)

18 Weichman, B.M., Muccitelli, R.M., Osborn, R.R., Holden, D.A., Gleason, J.G. and Wasserman, M.A.: In vitro and in vivo mechanisms of leukotriene-mediated bronchoconstriction in the guinea pigs. J. Pharmacol. Exp. Ther. 222, 202208 (1982)

19 Hanna, C.J., Bach, M.K., Pare, P.D. and Schellenberg, R.R.: Slow-reacting substances (leuko- trienes) contract human airway and pulmonary vascular smooth muscle in vitro. Nature 290 . 343-344 (1981)

20 Anderson, W.H., O'Donnel, M., Simko, B.A. and Welton, A.F.: An in vivo model for measuring antigen-induced SRS-A-mediated bronchoconstriction and plasma SRS-A levels in the guineapig. Br. J. Pharmacol. 78, 67-74 (1983)

21 Schneider, M.E. and Drazen, J.M.: Comparative in vitro effects of arachidonic acid metabolites on tracheal spirals and parenchymal strips. Amı. Rev. Resp. Dis. 121, 835-842 (1980)

22 Hamberg, H., Svensson, J., Hedqvist, P., Strandberg, K. and Samuelsson, B.: Adv. Prostaglandin Thromboxane Res. 1, 495 (1976)

23 Sanchez-Crespo, M., Alonso, F., Inarrea, P., Alvarez, $V$. and Egido, J.: Vascular actions of synthetic PAF-acether (a synthetic plateletactivating factor) in the rat: Evidence for a platelet independent mechanism. Immunopharmacology 4, 173-185 (1982)

24 Bonnet, J., Thibaudeau, D. and Bessin, P.: Dependency of PAF-acether induced bronchospasm on the lipoxygenase pathwayin the guinea pig. Prostaglandins 26, 457-466 (1983)

25 Vargaftig, B.B., Lefort, J., Chignard, M. and Benveniste, J.: Platelet-activating factor induces a platelet-dependent bronchoconstriction unrelated to the formation of prostaglandin derivatives. Eur. J. Pharmacol. 65, 185-192 (1980)

26 Demopoulos, C.A., Pinckard, R.N. and Hanahan, D.J.: Platelet-activating factor, evidence for $1-0$ alkyl-2-acetyl-sn-glyceryl-3-phosphoryl choline as the active component (a new class of lipid chemical mediators). J. Biol. Chem. 254, 93559358 (1979)

27 Halonen, M., Palmer, J.D., Lohman, C., McManns, L.M. and Pinckard, R.N.: Differential effects of platelet depletion on the physiologic alteration of $\lg E$ anaphylaxis and acetyl ether phosphorvlcholine infusion in the rabbit. Am. Rev. Resp. Dis. 124, 416-421 (1981)

28 Vargaftig, B.B., Chignard, M., Benveniste, J., Lefort, J. and Wal, F.: Background and present status of research on platelet-activating factor (PAF-acether). Ann. N.Y. Acad. Sci. 37, 119-137 (1981)

29 Voelkal, N.F., Worthen, S., Reaves, J.T., Henson, P.M. and Murphy, R.C.: Nonimmunological production of leukotriene induced by plateletactivating factor. Science 218, 286-288 (1982) 